\title{
Perancangan Alat Pemberi Pakan Ikan Otomatis Menggunakan Arduino Berbasis Android (Studi Kasus : Toko Arapaima Aquarium)
}

\author{
Hendra $^{1}$, Andhika ${ }^{2}$ \\ ${ }^{1}$ Universitas Universal, Fakultas Ilmu Komputer \\ Kompleks Maha Vihara Duta Maitreya, Bukit Beruntung, Sei Panas, Batam 29456 \\ E-mail: wesleyhendra01@gmail.com
}

\begin{abstract}
Abstrak
Pemberian pakan kepada ikan adalah suatu hal yang terpenting dalam membudidayakan ikan, dengan secara rutin pemberian pakan kepada ikan, maka ikan akan dapat terus berkembang biak. Pada umumnya proses pemberian pakan masih membutuhkan sumber daya manusia yang sifatnya masih manual, sehingga akan kesulitan dan mengganggu aktifitas manusia itu sendiri, jika proses yang dilakukan harus menebarkan pakan ke akuarium ketika seseorang tidak ditempat, oleh karena itu saat ini telah berkembang teknologi IOT (Internet of Thing) yang dapat mempermudah aktifitas manusia dengan sistem kendali jarak jauh. Proses pemberian pakan dengan sistem kendali jarak jauh dilakukan menggunakan android, sehingga mempermudah dan menghemat waktu seseorang dalam proses pemberian pakan tanpa harus ditempat. Alat sistem kontrol yang digunakan yaitu arduino ESP8266 sebagai platform pengendali mikro single board, sehingga alat kontrol tersebut dapat berfungsi untuk mengkoneksikan jaringan WI-FI. Proses mengkoneksikan perangkat arduino ESP8266 dengan smartphone dilakukan dengan menggunakan broker sebagai hosting, broker yang digunakan adalah MQTT (Message Queuing Telemetry Transport), MQTT adalah sebuah protokol yang berjalan diatas stack $\mathrm{TCP} / \mathrm{IP}$ dan dirancang khusus untuk machine to machine yang tidak memiliki alamat khusus. Sistem kerja broker MQTT adalah dengan menerapkan publish sebagai pengirim data, subcribe sebagai penerima data, dan topic sebagai hosting data broker.
\end{abstract}

Kata kunci: IOT (Intenet of Thing), Android, MQTT (Message Queuing Telemetry Transport), Arduino.

\begin{abstract}
Feeding fish is the most important thing in raising fish, with regular feeding to fish the fish will be able to continue to breed, In general, the process of feeding still requires human resources that are still manual, so that it will be difficult and disrupt human activity itself, if the process carried out must spread the food in the aquarium when someone is not in place, Therefore, currently IOT (Internet of Thing) technology has been developed which can facilitate human activities with remote control systems. The process of feeding with a remote control system is done using android, so as to simplify and save someone's time in the process of feeding without having to be in place. The control system used is Arduino ESP8266 as a single board micro controller platform, so that the control device can function to connect the WI-FI network. The process of connecting an Arduino ESP8266 device with a smartphone is done using the broker as hosting, the broker used was MQTT (Message Queuing Telemetry Transport), $M Q T T$ is a protocol that runs on the TCP / IP stack and is designed specifically for machine to machine that does not have a specific address. MQTT broker's working system is to implement publish as data sender, subcribe as data recipient, and topic as hosting data broker.
\end{abstract}

Keywords: IOT (Intenet of Thing), Android, MQTT (Message Queuing Telemetry Transport), Arduino. 


\section{Pendahuluan}

Pemberian pakan ikan adalah salah
satu hal yang terpenting dalam
membudidayakan ikan, dengan adanya
pemberian pakan, ikan dapat terus
berkembang biak dan dapat di perjualbelikan. Maka pemelihara harus secara rutin memberi pakan kepada ikan setiap hari dengan jumlah tertentu sesuai dengan banyaknya ikan yang dipelihara, akan tetapi pemberian pakan ikan pada saat ini umumnya orang masih sangat bergantung pada sumber daya manusia untuk pemberian yang sifatnya masih manual. Menurut penelitian (Nulhakim 2014) dengan cara tersebut maka ikan yang dipelihara dalam akuarium harus diperhatikan waktu pemberian pakannya sehingga ikan tersebut membutuhkan jadwal pemberian pakan yang teratur dan terus menerus. Namun karena kesibukan atau kegiatan lain dan di luar dugaan, seringkali menjadi kendala pada saat pemberian pakan pada ikan di akuarium tersebut. Kendala ketika seseorang harus berpergian jauh hingga memakan waktu yang lama sampai berhari-hari, pasti akan berpikir bagaimana dengan keadaan ikanikan yang dipelihara dan bagaimana cara agar bisa memberi makan ikan-ikan tersebut dengan terus menerus atau terjadwal tanpa harus mengganggu aktivitas sehari-hari. Cara pemberian pakan ikan saat ini masih sederhana, yaitu dengan tangan menyebar pakan ikan langsung ke kolam akuarium atau tambak.

Pada saat ini telah berkembang alat pemberi pakan yang telah dijual di tokotoko ikan yaitu Automatic Feeder yang fungsi utamanya adalah memberi pakan ikan secara otomatis dengan menyetel waktu, berdasarkan penelitian (Jumalli and M Tang 2013) alat automatic feeder yang sudah ada ternyata masih terdapat beberapa kekurangan-kekurangan (kapasitas wadah pakan yang sedikit, pengaliran pakan yang sering tersendat, dan dinamo yang digunakan masih kurang akurat). Dengan melihat beberapa kekurangan-kekurangan tersebut maka dilakukan upaya untuk memodifikasi alat automatic feeder yang sudah ada, sehingga alat tersebut dapat diterapkan dengan optimal (kapasitas wadah pakan yang besar, pengaliran pakan yang lancar tidak mengalami tersendat, dan dinamo yang dibutuhkan lebih tepat dan akurat). Hal ini berarti pada automatic feeder tingkat kesalahannya masih sedikit dan masih bisa ditoleransi, itu berarti alat ini masih layak digunakan dalam budidaya terutama yang ingin melakukan pemberian pakan dengan sistem otomatisasi dalam suatu usaha budidaya.

Dari penelitian yang sudah ada menurut (Nur, Hasim, and Ramalingam 2017) Ada beberapa kelemahan yang ada pada pemasok ikan otomatis saat ini. Salah satu masalah dari sebagian besar pengumpan ikan adalah ketidakmampuan mereka untuk memeriksa fungsi pengumpan mereka dan risiko kembali ke ikan mati karena kegagalan fungsi pada mesin pengumpan. Kelemahan lainnya adalah, di mana pengumpan ikan memberi makan ikan terlalu sedikit atau terlalu banyak makanan, sehingga membahayakan kesehatan ikan dari kelaparan atau makan berlebih. Ada dua masalah utama yang diidentifikasi di sebagian besar sistem pemberian makan ikan seperti jumlah makanan yang disebarkan. Setiap pemberi makan ikan otomatis memiliki jumlah makanan yang berbeda untuk disebarkan ke ikan. Ini bisa menyebabkan makan berlebih atau kelaparan mendadak. Makanan berlebih bisa mencemari tangki ikan dan dapat menyebabkan kerusakan dan kurangnya pemantauan waktu nyata, beberapa pemilik ikan mungkin jauh dari ikan untuk jangka waktu yang lama. Dalam situasi seperti itu, pemilik ikan tidak akan tahu tentang kondisi ikan mereka. Hal ini dapat menyebabkan ketidaktahuan tentang masalah yang terjadi di rumah seperti kerusakan fungsi pengumpan mereka atau perubahan mendadak dalam perilaku ikan. 


\section{Tinjauan Literatur}

Dari Penelitian (Nur et al. 2017) yang berjudul "Developing fish feeder system using Raspberry Pi" menjelaskan tentang Raspberry Pi bertindak sebagai perantara antara antarmuka web dan pengumpan ikan. Kode untuk pengumpan ikan sedang diprogram menggunakan Python. Kode yang dapat ditulis dan dijalankan di Raspberry Pi. Kode-kode ini akan ditulis untuk menghubungkan ke pemasok ikan. Kode akan dijalankan ketika pengguna mengirim perintah dari antarmuka web. Raspberry Pi kemudian akan mengirim perintah ke pengumpan ikan. Basis data untuk otentikasi juga disimpan di Raspberry Pi. Basis data ini untuk memastikan hanya pengguna yang diautentikasi yang dapat mengakses pengumpan ikan. Raspberry $\mathrm{Pi}$ juga memungkinkan pengguna untuk mengakses pengumpan ikan menggunakan internet. Raspberry Pi memastikan pengumpan ikan tetap terhubung ke jaringan.

\section{Metodologi}

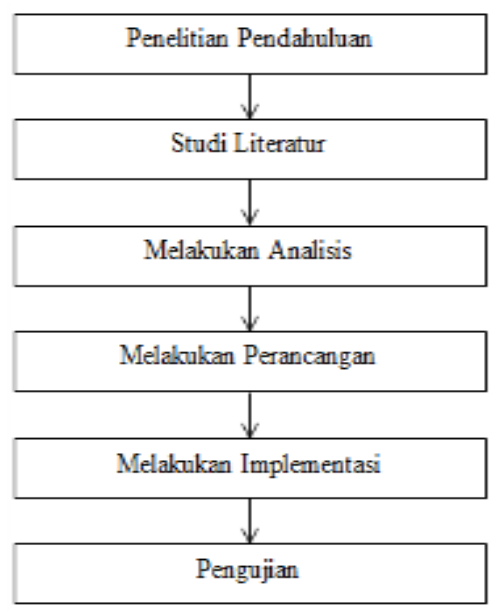

\section{Penelitian Pendahuluan}

Penelitian ini dimulai dengan penelitian pendahuluan yang bertujuan mengidentifikasi topik penelitian, mengidentifikasi objek yang akan diteliti, dan mengidentifikasi masalah yang ada.
Lalu dari penelitian (Weku et al. 2015) dari jurnalnya dengan Judul "Rancang Bangun Alat Pemberi Pakan Ikan Otomatis Berbasis Mikrokontroler". Menjelaskan sistem alat dapat memberi pakan secara otomatis sesuai pilihan jadwal yang telah diatur sebelumnya alat pemberi pakan ikan otomatis mampu mengirimkan sms pemberitahuan ketika pakan telah diberikan dan ketika tampungan dalam keadaan kosong/habis. Sensor photodioda dapat bekerja dengan baik dalam hal membaca keadaan tampungan ketika tampungan kosong/habis. Alat dapat mengontrol berat pakan yang akan diberikan sesuai pilihan takaran yang telah diatur. Jaringan provider dapat mempengaruhi kecepatan pengiriman sms. Tekanan penampung tidak mempengaruhi berat pakan yang akan diberikan.

\section{Studi Literatur}

Pada tahap ini, peneliti melakukan studi literatur, yaitu proses mengumpulkan referensi dari berbagai e-book dan jurnal yang berkaitan dengan topik yang dibahas dalam penelitian ini.

\section{Melakukan Analisis}

Pada tahap ini, peneliti menganalisis masalah yang dihadapi dan menganalisis kebutuhan user untuk mengembangkan solusi dari permasalahan yang ada. Hasil dari fase analisis ini kemudian digunakan untuk membantu mendesain alat dan juga merancang sistem pemberian pakan kepada ikan.

\section{Melakukan Perancangan}

Tahapan berikutnya adalah merancang aplikasi yang akan dibuat. Perancangan menggunakan arduino, Pada tahap ini juga dilakukan perancangan desain antarmuka aplikasi yang dibuat. 


\section{Melakukan Implementasi}

Pada tahap ini, pengembangan alat didasarkan pada desain dari tahap sebelumnya. Aplikasi yang dibuat adalah aplikasi berbasis mobile, sehingga pengembangan aplikasi dalam tugas akhir ini menggunakan bahasa pemrograman $\mathrm{C}++$. Arduino ESP8266 dan Android MQTT digunakan untuk konektifitas antara aplikasi dengan alat arduino.

\section{Hasil dan Pembahasan}

\section{Studi Literatur}

Dalam tahap ini peneliti melakukan wawancara dan observasi. Wawancara dilakukan dengan pihak manajemen toko arapaima aquarium batam, untuk mendapatkan informasi mengenai kebutuhan aplikasi yang akan dibuat beserta permasalahan - permasalahan yang saat ini dihadapi. Hasil dari wawancara dengan pihak manajemen. Peneliti kemudian melakukan studi literatur untuk mengumpulkan informasi yang terkait dengan topik yang akan dibahas dalam penelitian ini, yakni arduino, Message Queuing Telemetry Transport, pemberian pakan, dan bahan bahan tambahan yang akan menjadi acuan dan dapat membantu penelitian.

\section{Perancangan Sistem}

Perancangan sistem adalah melakukan perancangan secara kesuluruhan terhadap rangkaian alat yang akan digunakan. Gambar 7 dibawah ini merupakan diagram blok sistem pemberian pakan ikan otomatis pada akuarium berbasis Arduino ESP8266.

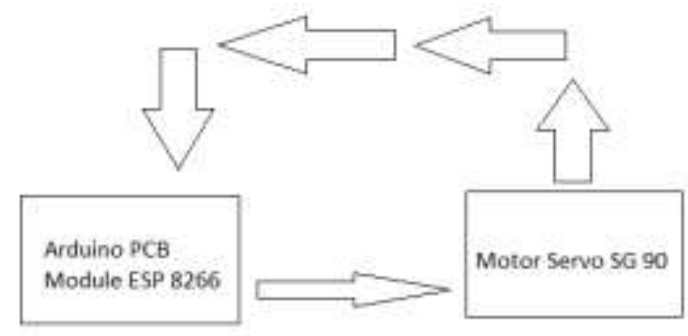

Gambar 1 Diagram Blok Sistem Pemberian Pakan Ikan Otomatis Pada Akuarium Berbasis Android

\section{Pengujian}

Page : 270-277

Tahapan terakhir adalah menguji alat pemberi pakan untuk mengetahui tingkat keberhasilan suatu program, sistem pengujian dilakukan menggunakan android dengan menguji pemberian pakan secara manual dan otomatis.

Berdasarkan diagram blok diatas prinsip kerja dari alat ini, yaitu ketika catu daya diaktifkan maka arduino pcb module esp8266 dan motor servo sg90 akan aktif. Waktu pemberian pakan yang sebelumnya telah diprogram di arduino akan berjalan sesuai dengan jam dan waktunya, karena sistem pemberian pakan terbagi menjadi 2 yaitu manual dan otomatis. Ketika pemberian pakan otomatis maka user tidak perlu mengontrol pemberian pakan, karena sistem akan bekerja ketika module esp8266 hidup dan mengontrol servo untuk pemberian pakan, pada saat servo telah bekerja maka sistem akan memberi informasi dan mengupdate waktu terakhir pemberian pakan. Begitu juga sama halnya saat pemberian pakan manual.

\section{Perancangan Biaya}

Perancangan biaya ini membahas tentang harga seluruh alat yang diperlukan untuk merancang sebuah aplikasi pemberi pakan ikan otomatis, sehingga user dapat mengetahui alat-alat apa yang perlu dibeli serta kisaran harga yang dijual dipasaran.

\begin{tabular}{|c|c|}
\hline Alat & Herge \\
\hline PCB 1adule ESP 8266 & $\operatorname{Ro} 5,5,500$ \\
\hline Motor Servo SG90 & $\mathrm{Re} .47 .000$ \\
\hline Wadal Pasan & Re, 2,000 \\
\hline Aquarim & Ro. 100,000 \\
\hline Total & Ro. 203,500 \\
\hline
\end{tabular}

Table 1 Perancangan Biaya 
Perancangan Mekanik Pakan Ikan Pada Akuarium

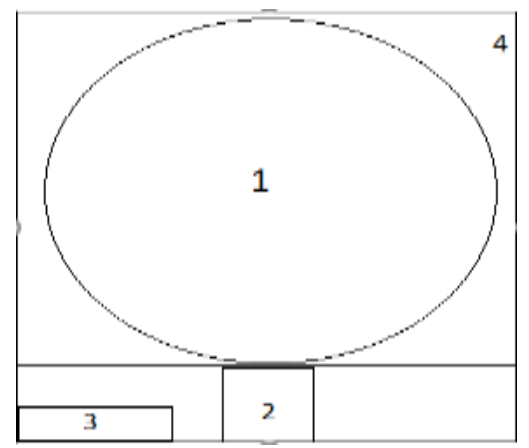

Gambar 2 Rancangan Bangun Pakan Ikan Pada Akuarium

Rancangan bangun pakan ikan otomatis pada akuarium dapat dilihat seperti gambar 8 diatas. Keterangan :

1. Wadah Pakan

2. PCB Module ESP8266

3. Motor Servo

4. Akuarium

\section{Perancangan Rangkaian Motor Servo}

Motor servo berfungsi sebagai penggerak tuas pemberi makan ikan pada akuarium, motor servo memiliki 3 pin yang akan dikoneksikan langsung ke module arduino ESP8266, rangkaian motor servo dapat dilihat pada gambar 9 dibawah.

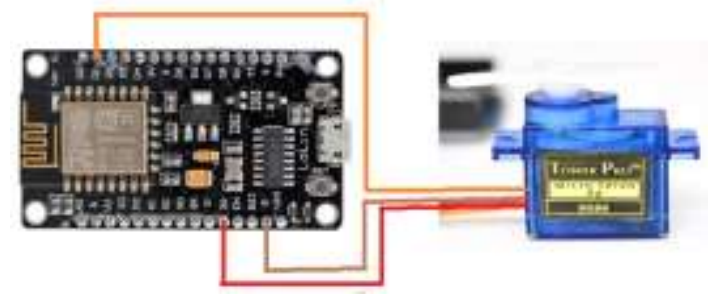

Gambar 3 Rangkaian Motor Servo Ke Arduino ESP8266

Koneksi pin motor servo pada arduino ESP8266 dapat dilihat pada tabel 4.

\begin{tabular}{|c|c|c|c|}
\hline $\begin{array}{l}\frac{\text { No Pin }}{\text { Servo }} \\
\text { Motor }\end{array}$ & $\frac{\text { Jenis Pin Motor }}{\text { Servo (Wama) }}$ & $\begin{array}{l}\text { No } \quad \text { Pin } \\
\text { Ardaino }\end{array}$ & $\begin{array}{l}\text { Keterangan koneksi pin motor } \\
\text { servo pada Arduino ESP8266 }\end{array}$ \\
\hline 1 & Gromed (Coklat) & GND & Ke pin GND Arduiro ESP8266 \\
\hline 2 & Power (Merab) & $3 \mathrm{~V}$ & Ke piil 3V Arduino ESP8266 \\
\hline 3 & Signal (Orange) & $\mathrm{DI}$ & Ke pin Dl Ardaino ESP8266 \\
\hline
\end{tabular}

Jurnal KomtekInfo, Vol.7 No.4 Tahun 2020

e-ISSN : 2502-8758 || p-ISSN : 2356-0010 DOI : $\underline{10.35134 / \text { komtekinfo.v7i4 }}$

Page : 270-277

Table 2 Koneksi Pin Motor Servo Pada Arduino

$$
\text { ESP8266 }
$$

\section{Rancangan Halaman Aplikasi}

Halaman pada aplikasi pemberian pakan yang sudah diberikan label berisi bagian yang menampilkan tombol button dan informasi. Rancangan halaman aplikasi ditampilkan pada gambar 10 .

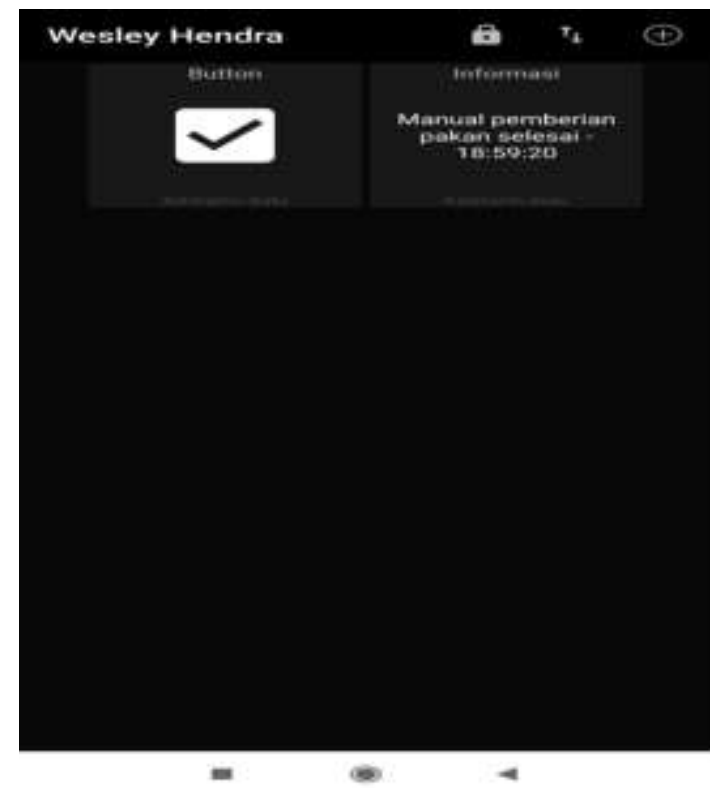

Gambar 4 Rancangan Halaman Aplikasi

\section{Rancangan Use Case Diagram}

Use Case Diagram dari aplikasi pemberian pakan ditunjukkan pada gambar 11. Aktor yang terlibat di dalam aplikasi pemberian pakan ini adalah user dan aplikasi android. User memiliki hak akses untuk membuka aplikasi dan menekan tombol button untuk proses pemberian pakan secara manual, sedangkan android aplikasi juga dapat melakukan pemberian pakan, tetapi hak akses dari android aplikasi hanya proses pemberian pakan secara otomatis, serta menampilkan halaman informasi waktu terakhir pemberian pakan, baik manual ataupun otomatis. 


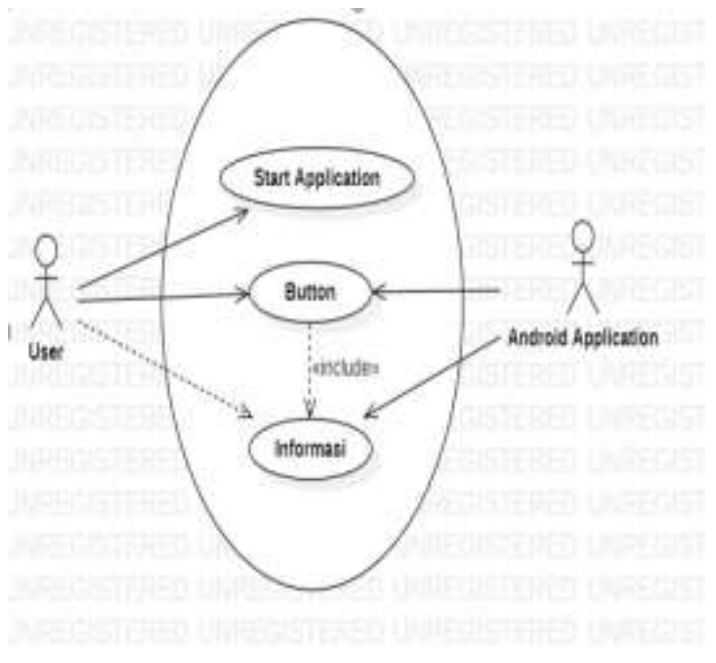

Gambar 5 Use Case Diagram

\section{Rancangan Activity Diagram}

Gambar 12 adalah activity diagram dari membuka aplikasi yang dilakukan oleh user, kemudian sistem akan menampilkan halaman aplikasi berupa button dan informasi, lalu user dapat melihat jam terakhir pemberian pakan dan kemudian menekan tombol button untuk menjalankan proses pemberian pakan secara manual, setelah proses pemberian pakan telah ditekan oleh user maka motor servo akan bekerja dengan memutar wadah pakan ikan secara 180 derajat, dan menginformasikan kepada user berupa tampilan halaman aplikasi jadwal terakhir pemberian pakan.

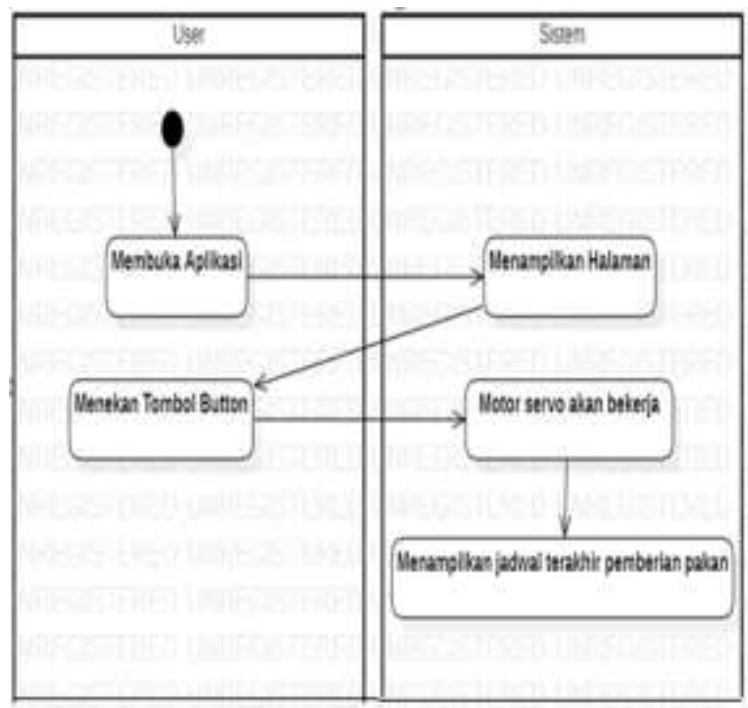

Gambar 12 Activity Diagram

\section{Rancangan Sequence Diagram}

Gambar 13 adalah sequence diagram dari proses pemberian pakan kepada ikan, terdiri dari user, aplikasi mobile, dan android mqtt. Pertama user membuka aplikasi kemudian di aplikasi mobile akan melakukan proses koneksi ke broker lalu di android mqtt akan mengkoneksikan topic (broker), publish (pengirim data), dan subcribe (penerima data) setelah semua sesuai, maka koneksi akan dapat saling sinkron data, kemudian android mqtt akan menampilkan halaman pemberian pakan ikan ke user, sehingga user dapat mengetahui jam terakhir ikan dikasih pakan, setelah mengetahui jam terakhir ikan makan, maka user dapat menekan tombol button untuk proses pemberian pakan kepada ikan secara manual di aplikasi mobile, sehingga di aplikasi mobile akan memproses aktifkan motor servo sg90 di android mqtt, ketika motor servo aktif dalam arti telah terkoneksi dengan listrik maka wadah pakan ikan akan memutar 180 derajat untuk menuang pakan ikan, sehingga android mqtt akan sinkron untuk menampilkan jadwal terakhir pemberian pakan ke ikan.

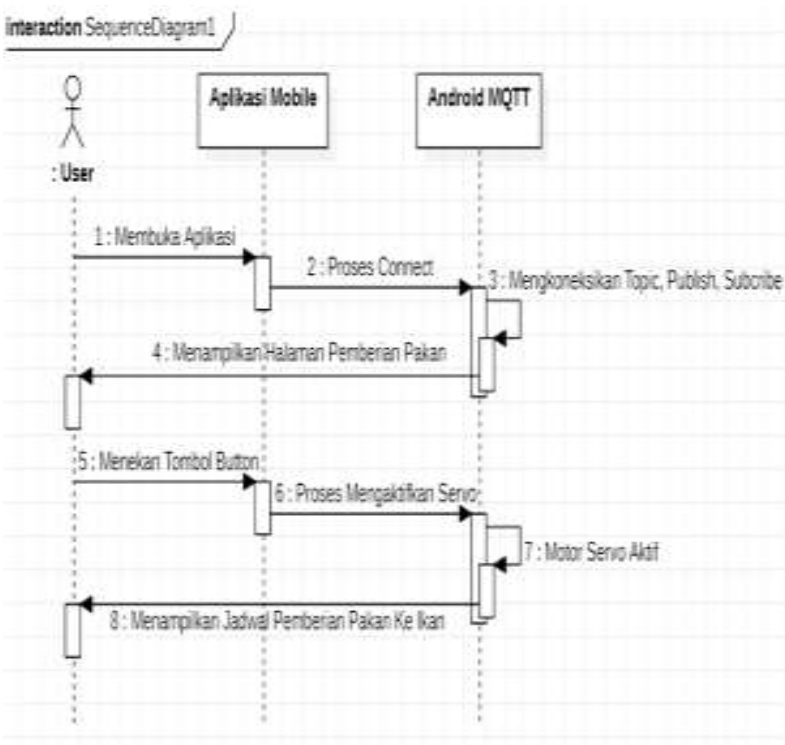

Gambar 6 Sequence Diagram 


\section{Kesimpulan dan Saran}

Berdasarkan hasil dalam penelitian ini, peneliti dapat menyimpulkan beberapa hal sebagai berikut :

1. Cara merancang alat kontrol pemberi pakan ikan secara jarak jauh adalah dengan menggunakan arduino ESP8266 dan motor servo SG90. Proses pemberian pakan ikan secara jarak jauh terbagi menjadi 2 yaitu otomatis dan manual. Proses pemberian pakan secara manual bekerja ketika user menekan tombol button di tampilan aplikasi sedangkan proses pemberian pakan secara otomatis bekerja ketika user melakukan settingan waktu di aplikasi arduino.

2. Sistem monitoring pemberian pakan ikan yang efektif dan efisien adalah dengan menggunakan aplikasi sebagai alat monitoring pemberian pakan ikan. Ketika proses pemberian pakan ikan telah berhasil, maka aplikasi akan memberikan informasi yang menampilkan jam terakhir pemberian pakan, sehingga user dapat mengetahui kapan terakhir pemberian pakan ke ikan.

Berdasarkan hasil dalam penelitian ini, terdapat beberapa saran untuk penelitian selanjutnya:

1. Aplikasi pemberian pakan dapat dikembangkan atau dihubungkan dengan sensor (mendeteksi sisa pakan) dan buzzer (alarm).

2. Ditambahkan camera dalam pemberian pakan di akuariumnya.

3. Tambahan fitur monitoring menggunakan camera dari aplikasi.

\section{Daftar Pustaka}

[1] Ahlina, Nuril. 2015. "Dengan Adanya Gangguan, Sistem Kontrol Lup Terbuka Tidak Dapat Bekerja Seperti Yang Diinginkan. Kontrol Lup Terbuka Dapat
Digunakan Dalam Praktek Hanya Jika Hubungan Antara Masukan Dan Keluaran Diketahui Dan Jika Tidak 5." 5-64.

[2] Anisah, Nurlaili, Ummu Radiyah, and Anton. 2016. "RANCANGAN SISTEM INFORMASI E-RECRUITMENT." 3(2):1-7.

[3] Ayu, Wirenda Sekar, Rizky Septendhi, Bayu Azi, Mervin T. Hutabarat, and Yana S. Raharja. 2018. "Android Application Design of Automatic Tablet Dispenser Using MQTT Protocol Communication."

[4] Galadima, Ahmad Adamu. 2014. "Arduino as a Learning Tool."

[5] Hunkeler, Urs, Hong Linh Truong, and Andy Stanford-clark. 2008. "MQTT-S A Publish / Subscribe Protocol For Wireless Sensor Networks."

[6] Jumalli, Selamat and Usman M Tang. 2013. "The Modificated of Automatic Feeder for Increasing Effectiveness of Fish Meal in Take."

[7] Muhammad, Muhammad and Ibrahim Hasan. 2016. "ANALISA DAN PENGEMBANGAN JARINGAN WIRELESS BERBASIS MIKROTIK ROUTER OS V . 5 . 20 DI SEKOLAH DASAR NEGERI 24 PALU.” 2(1).

[8] Nulhakim, Lukman. 2014. "OTOMATIS BERBASIS MIKROKONTROLER ATMEGA16."

[9] Nur, Hidayatul, Binti Hasim, and Mritha Ramalingam. 2017. "Developing Fish Feeder System Using Raspberry Pi."

[10] Suendri. 2018. "Implementasi Diagram UML (Unified Modelling Language) Pada Perancangan Sistem Informasi Remunerasi Dosen Dengan Database Oracle (Studi Kasus: UIN Sumatera Utara Medan).” 6341(November):1-9.

[11] Syafa, Lailis, Agus Eko Minarno, Fauzi Dwi, Setiawan Sumadi, Dwi Anggraini, and Puspita Rahayu. 2019. "ESP 8266 For Control And Monitoring In Smart Home Application." 2019 International Conference on Computer Science, Information Technology, and Electrical Engineering (ICOMITEE) 1:123-28.

[12] Syarif, Muhamad, Wahyu Nugraha, Program Studi, Sistem Informasi, Akuntansi Kampus, Kota Pontianak, Fakultas Teknologi Informasi, Universitas Bina, Sarana Informatika, and Kalimantan Barat. 2020. "PEMODELAN DIAGRAM UML 276 
SISTEM PEMBAYARAN TUNAI PADA TRANSAKSI E-COMMERCE." 4(1).

[13] Weku, Hendra S., Eng Vecky C. Poekoel, Reynold F. Robot, and M. Eng. 2015. "Rancang Bangun Alat Pemberi Pakan Ikan Otomatis Berbasis Mikrokontroler." 5(7):54-64.

[14] Widya, Adi Rusdi, Ahmad Turmudi Zy,
Jurnal KomtekInfo, Vol.7 No.4 Tahun 2020

e-ISSN : 2502-8758 || p-ISSN : 2356-0010 DOI : $\underline{10.35134 / \text { komtekinfo.v7i4 }}$ Page : 270-277

Teknik Informatika, Universitas Pelita Bangsa, and Teknik Informatika. 2019. "PERANCANGAN MONITORING MACHINE CONDITION DENGAN." (September).

[15] Xia, Feng, Laurence T. Yang, Lizhe Wang, and Alexey Vinel. 2012. "Internet of Things." 1101-2. 